\title{
El romanticismo (anticapitalista) en La teoría de la novela'
}

Fecha de recepción: 16/7/2019. Fecha de aceptación: 31/7/2019.

\section{Resumen}

La visión romántica se define como una forma específica de crítica de la modernidad capitalista, en nombre de los valores e ideales de un pasado precapitalista, premoderno. Este artículo pretende mostrar cómo el espíritu romántico así definido se encuentra en el corazón de los primeros escritos de Lukács entre 1911 y 1917, en el momento en que escribió La teoría de la novela.

Palabras clave: György Lukács; novela; romanticismo; teoría literaria; Lucien Goldmann

Romanticism (anticapitalist) in The Theory of the Novel

\begin{abstract}
The romantic vision is defined as a specific form of critique of capitalist modernity, on behalf of values and ideals from a precapitalist, premodern past. This article aims to show how the romantic spirit so defined lies at the heart of Lukács's early writings between 1911 and 1917, at the time when he wrote The Theory of the Novel.
\end{abstract}

Keywords: György Lukács; novel; romanticism; literary theory; Lucien Goldmann

1 Este artículo fue publicado en el octavo número de Romanesques (2016), dedicado al centenario de la publicación de La teoría de la novela de György Lukács. Traducido del francés por Juan Manuel Lacalle. 


\section{Introducción}

En este ensayo abordaremos La teoría de la novela desde una concepción del romanticismo que hemos ido elaborando a lo largo de varias décadas y en varios escritos, particularmente en Rebelión y melancolía: el romanticismo a contracorriente de la modernidad (Löwy y Sayre: 2008). ${ }^{2}$ Nuestra concepción va en contra de las ideas tradicionales del romanticismo como una corriente puramente literaria o un período limitado al comienzo del siglo XIX. Lo concebimos en términos más extensos, como una "visión del mundo" -en el sentido que daba a ese término el sociólogo marxista de la cultura Lucien Goldmann-, que se despliega en distintos dominios: la literatura y el arte, pero también la filosofía, la religión, las ciencias humanas y la teoría política. Esa vasta corriente cultural se caracteriza como una protesta, en nombre de valores sociales y culturales del pasado, contra la civilización capitalista moderna. Por lo tanto, la visión romántica constituye una forma específica de crítica de la "modernidad", es decir, de la civilización global de múltiples facetas que se desarrolla con el capitalismo. La especificidad de la crítica romántica viene de que se hace en nombre de los valores e ideales sacados de un pasado precapitalista, premoderno, mientras que otras críticas se hacen, en cambio, en nombre del "progreso".

Si situamos el nacimiento del romanticismo a mediados del siglo XVIII, cuando el capitalismo se constituye en tanto sistema, no se terminaría a lo largo del siglo XIX, como quisieran ciertas ideas convencionales, sino que continuaría, sobre formas siempre nuevas, hasta nuestros días. Dentro de esa nebulosa cultural encontramos una pluralidad de orientaciones sociopolíticas, desde el romanticismo conservador o reaccionario, que aspira a la restauración de las jerarquías del Antiguo Régimen, hasta el romanticismo revolucionario, cuyo objetivo no es un retorno hacia atrás, sino un "desvío" a través del pasado comunitario hacia un futuro utópico.

La sensibilidad romántica se funda sobre la experiencia de la pérdida, la convicción dolorosa de que en la realidad moderna se ha perdido algo valioso, tanto a nivel del individuo como de la humanidad. El presente carece de ciertos valores humanos esenciales que fueron alienados: valores cualitativos, por oposición al valor de cambio que predomina en la modernidad. Esa alienación, vivamente sentida, con frecuencia es experimentada como un exilio y, así, la nostalgia se aloja en el corazón de la visión romántica. Eso que falta en el presente, existía en un pasado más o menos lejano, real o imaginario / mítico, frecuentemente idealizado a pesar de ser real. El rasgo determinante de ese pasado es su diferencia con el presente. Se trata de una época en que las alienaciones del presente todavía no existían.

La nostalgia por ese paraíso perdido está acompañada generalmente por una búsqueda de eso que se perdió; una tentativa de recrear el pasado ideal, aunque

2 Véase también nuestro estudio complementario: Löwy y Sayre (2010). Sobre la génesis y el desarrollo de nuestro trabajo sobre el romanticismo, véase Sayre (2011). 
a menudo no haya ningún deseo de reproducirlo literalmente. Se encuentra también una forma "resignada" de romanticismo. La oposición romántica a la modernidad rara vez consiste en un cuestionamiento del sistema social como un todo, sino que la mayoría de las veces reacciona contra determinados aspectos experimentados como insoportables. Los temas que aparecen de manera repetida en las obras románticas son: el "desencantamiento" del mundo (Entzauberung der Welt) -concepto difundido por Max Weber-, la cuantificación, la mecanización y la abstracción racionalista -elementos analizados también por Weber-y, finalmente, la disolución de los lazos comunitarios en la modernidad capitalista.

\section{El Romanticismo en los escritos de juventud de Lukács}

Esta concepción del romanticismo la hemos desarrollado tomando como punto de partida una noción que Lukács mismo (más tarde en su carrera, cuando ingresó al marxismo) aplicó a cierta forma de oposición al capitalismo, que estimaba superada por el marxismo: "el anticapitalismo romántico". En esa categoría incluía algunos de sus propios escritos de juventud. Ahora bien, en efecto, el romanticismo tal como lo hemos definido se encuentra en el corazón de sus primeros escritos, durante los años 1911-17, cuando escribe La teoría de la novela. Se trata de la visión del mundo dominante en los círculos intelectuales de los que participa, tanto en Hungría, en la "Escuela Libre de las Ciencias del Espíritu" y el "Círculo de los Domingos" (Karl Mannheim, Belá Balász, Belá Fogarasi), como en Alemania, en el "Círculo Max Weber" de Heidelberg (Georg Simmel, Robert Michels, Ernst Bloch). Uno de los participantes de este último, el sociólogo Paul Honigsheim -en aquella época, joven estudiante- describió, varias décadas más tarde, la atmósfera cultural de ese grupo de amigos que se reunían todos los domingos en la casa de Max y Marianne Weber: "una tendencia a alejarse del modo burgués de vida, la cultura de la ciudad, la racionalidad instrumental, la cuantificación, la especialización científica [...] Ese neorromanticismo, si se lo puede llamar así, estaba unido a los viejos románticos por múltiples [...] pequeñas corrientes de influencia [...] El neorromanticismo bajo sus formas diversas estaba representado en Heidelberg [...] y sus adeptos sabían a qué puerta tocar: la puerta de Max Weber". La literatura rusa ocupaba un lugar esencial en esos intercambios informales: "No recuerdo una sola conversación de domingo en que el nombre de Dostoievski no fuera mencionado. Quizás aún más presente, incluso candente, era la necesidad de compromiso con Tolstoi". La teoría de la novela parece estar directamente en continuidad con esas discusiones. En cuanto a Lukács, Honigsheim lo describe como un joven intelectual "totalmente opuesto a la burguesía, el liberalismo, el Estado constitucional, el parlamentarismo, el socialismo revisionista, la Ilustración, el relativismo y el individualismo" (Honigsheim, 1968: 24, 79, 85).

Uno de los primeros escritos importantes del joven Lukács, Historia de la evolución del drama moderno, escrito en 1909, no fue publicado integralmente más que en húngaro (1911). Sin embargo, un capítulo apareció en alemán en la 
revista de Max Weber, Archiv für Sozialwissenschaft, en 1914. Ese texto retoma la problemática romántica de la ciencia social alemana, dándole un sesgo más radical. Aquí aparece por primera vez bajo su pluma el concepto de cosificación (Versachlichung) -que ocupará un lugar central en su obra marxista- para describir "la tendencia a la despersonalización y a la reducción de lo cualitativo a lo cuantitativo" en la sociedad burguesa. También critica la racionalización, "ese deseo de reducir todo a cifras y fórmulas" y el intelectualismo burgués que "tiende a descomponer toda comunidad y aislar a los seres humanos unos de otros” (Lukács, 1961: 271, 283, 287).

Esas reflexiones sociológicas, a medio camino entre Simmel, Weber y Marx, están ausentes en su compilación de ensayos de 1910, El alma y las formas. La mayor parte de los autores de los que se ocupa-Novalis, Kierkegaard, Theodor Storm, Stefan George, Paul Ernst- pertenecen a la corriente romántica, pero la argumentación de Lukács se sitúa sobre un terreno más bien metafísico. El romanticismo (antiburgués) toma aquí la forma de una oposición "trágica" entre los valores (premodernos) auténticos y el mundo empírico, donde "todo fluye y se mezcla, sin inhibiciones, en mezcla impura”. Su principal reproche a Novalis es no haber comprendido el abismo infranqueable entre el universo unívoco y claro de las formas poéticas y el universo equívoco y corrompido de la realidad empírica. Los románticos “crearon un mundo homogéneo, unitario en sí mismo y orgánico, y lo identificaron con el real” (Lukács, 1985: 244, 90).

Desde el punto de vista de las ideas sociales y políticas, el joven Lukács ya se interesa en el marxismo, que considera como una síntesis grandiosa: "la síntesis más implacable y rigurosa quizás desde el catolicismo de la Edad Media, que aguarda aún encontrar sus Giottos y Dantes -una comparación osada, que solo un espíritu romántico podría imaginar" (Lukács, 1911: 156-7)-. Sin embargo, sus simpatías profundas se dirigen hacia las corrientes románticas revolucionarias más radicales, como el anarco-sindicalismo de Georges Sorel y su discípulo húngaro Erwin Szábo.

La teoría de la novela es una obra compleja y de múltiples facetas, "contradictoria” (un término utilizado por Lukács en su Prólogo de 1962), que no se puede reducir a una sola idea, un solo principio estético o filosófico, o explicada por una sola clave interpretativa. Somos conscientes de que el romanticismo -en el sentido que atribuimos a esa palabra- no es la única dimensión de ese escrito pluridimensional y que algunas partes del argumento parecen escapar a nuestra matriz de lectura. También somos conscientes de que el término "capitalismo" no aparece en absoluto en el ensayo, y que eso que designa como "romanticismo" no tiene más que un vínculo parcial e indirecto con lo que entendemos por ese concepto.

Si insistimos en nuestra contribución sobre la "dimensión romántica” (anticapitalista) del ensayo es porque nos parece esencial para comprender su "estructura significativa”. Nos parece-y es nuestra hipótesis de trabajo- que esa sensibilidad romántica preside a la construcción del texto, a su lógica global, a la dialéctica entre el pasado, el presente y el futuro que constituye su estructura principal. 
Como hemos sugerido más arriba, esa sensibilidad se encuentra en el conjunto de los escritos de juventud de Lukács. Pensamos también que el juicio retrospectivo de Lukács sobre su obra y los análisis propuestos por Lucien Goldmann tienden a confirmar esa hipótesis.

\section{Los comentarios tardíos de Lukács sobre La teoría de la novela}

En su prólogo de 1962 a la reedición de La teoría de la novela, Lukács describe su estado intelectual en el momento de la redacción -el comienzo de la Primera Guerra Mundial- como "una permanente desesperanza ante la situación mundial" y un "rechazo vehemente y global", tanto de la guerra como de la sociedad burguesa de la época. Si consideraba con cierta satisfacción la probable caída del zarismo y de los Hohenzollern y los Habsburgo -las monarquías de Europa central- no podía evitar hacer la pregunta irónica: “¿quién nos salva de la civilización occidental?" (Lukács, 1985: 281). ${ }^{3}$

Retrospectivamente, el autor define el punto de vista de La teoría de la novela como un pesimismo de coloración ética e inspiración kierkegaardiana, comparable a algunos escritos de Sorel, Karl Löwith o Thomas Mann. ¿Cómo definir esa visión social del mundo? Desde el punto de vista de la filosofía social, afirma, "La base filosófico-histórica de esas teorías es la actitud del anticapitalismo romántico, tan contradictoria en lo filosófico como en lo político" (290). La evaluación de Lukács de ese romanticismo en 1962 está lejos de ser puramente negativa: está en el origen -por ejemplo en el joven Carlyle o en Cobbett- de una "crítica de la crueldad y la anticultura del capitalismo naciente, y a veces incluso de una forma anticipatoria de la crítica socialista [...]" (290). En Alemania se transformó poco a poco en apología reaccionaria de los Hohenzollern. Este no es el caso, se apresura a agregar Lukács, del autor de La teoría de la novela: su oposición al carácter bárbaro del capitalismo no tiene nada de conservadora. Más bien proviene de un utopismo "sumamente ingenuo": "la esperanza en que la caída del capitalismo, la caída de las categorías económico-sociales muertas, antivitales, identificada con la del capitalismo, dé de sí sin más una vida natural, digna del hombre" (290). La esperanza de un "mundo nuevo" es precisamente el tema de la conclusión del libro, a propósito de Tolstoi y Dostoievski.

Tratando de identificar de más cerca el contenido de ese romanticismo utópico, Lukács lo define a través de una fórmula un poco torpe: una mezcla entre una ética "de izquierda", "orientada a la revolución radical", y una epistemología "de derecha", es decir, "una interpretación de la realidad de tipo tradicional y convencional" (291-2). Cita como ejemplos de esa posición híbrida a algunos autores de los años '20 como Ernst Bloch, Walter Benjamin y Theodor W. Adorno. Lukács tiene razón en la medida en que esos autores son “marxistas románticos", pero

3 De aquí en adelante, todas las citas de La teoría de la novela incluirán únicamente el número de página entre paréntesis. 
la caracterización de su método o "epistemología" como "de derecha" no tiene mucho sentido. La diferencia entre ellos y el joven Lukács de La teoría de la novela es que este aún no era marxista. Por otra parte, el Lukács marxista de 1962 se aleja de su romanticismo de juventud y, más adelante, reprocha a Ernst Bloch mantenerse "inconmoviblemente fiel a su síntesis de ética de izquierda y epistemología de derecha” -en su visión romántica del mundo-y, peor aún, basarse en La teoría de la novela durante el debate sobre el expresionismo de los años ‘30 con el fin de que "polemice contra el marxista György Lukács” (292, 288).

\section{Los comentarios de Lucien Goldmann}

En la edición francesa de La teoría de la novela apareció, con el prólogo de Lukács, un texto sobre los primeros escritos de este último por Lucien Goldmann -un discípulo de Lukács que interpreta la obra del maestro de una manera completamente original-. Mientras que el Lukács de 1962 daba una mirada retrospectiva sobre los escritos premarxistas de los que había renegado durante mucho tiempo, esforzándose por situarlos y diferenciarlos en relación con su perspectiva marxista del momento, Goldmann (marxista pero independiente y heterodoxo) buscaba mostrar la pertinencia y la gran utilidad del Lukács premarxista para una sociología no dogmática de la literatura y de la cultura.

Goldmann se dirige en seguida a El alma y las formas, subrayando su importancia en tanto ruptura con la filosofía universitaria alemana, devenida bastante estéril. Su análisis lo inserta en una filiación filosófica de la visión del mundo trágico, desde Pascal al existencialismo contemporáneo, pasando por Kant. Volviéndose, a continuación, sobre La teoría de la novela, Goldmann señala que esta se vincula con El alma y las formas "como la aplicación de los mismos principios a nuevos dominios". La obra introduce una nueva dimensión crucial al abordar los diferentes géneros épicos, porque "en la literatura épica las 'formas' son la expresión de las relaciones múltiples y complejas que mantienen al alma con el mundo, que deviene, al lado del alma y a su mismo nivel, su fundamento esencial..." (Goldmann, 1963: 169, 170).

La naturaleza del "mundo" en donde la épica se desarrolla es constitutiva, al igual que "el alma" del sujeto -el "héroe" y el autor- que la encuentra. En la novela -forma moderna de la épica- "en relación con los valores auténticos, el mundo es convencional y radicalmente degradado, extraño a todo eso que podría ser patria, un hogar para el alma”. El héroe de la novela, en cambio, es un ser "problemático" porque, permeado por el mundo degradado, queda ligado a los valores verdaderos "sobre una moda degradada e indirecta" o "demónica" (Goldmann, 1963: 174). El autor, en tanto tal, es el portador positivo de esos valores, pero solamente en tanto “deber-ser"; y su “ironía” (es el término utilizado por Lukács en su texto) deriva tanto de su conciencia de la "insuficiencia" de su héroe, como del "aspecto conceptual de los valores tal como existen en su propia conciencia” (Goldmann, 1963: 175). 
Goldmann desarrolla entonces su argumento principal, que es hacer valer la relación de homología entre los rasgos estructurales de la novela extraídos por el joven Lukács, y el análisis marxista de la "cosificación" o del "fetichismo de la mercancía" en la sociedad capitalista. En sus palabras no se encuentra ninguna mención del romanticismo ni de una visión romántica, y algunos aspectos de su argumentación podrían parecer excluirlo -en particular, la idea de que la sociedad capitalista tiende a reducir la conciencia de los individuos "a un simple reflejo pasivo de la infraestructura” (Goldmann, 1963:181)-. No obstante, los análisis de Goldmann en el ensayo son más complejos, y desmienten una interpretación simplista de esta última afirmación. Porque el escritor -ese autor de la novela que está regido por el "deber-ser"- queda para él adherido al "valor de uso" en virtud de su labor de artista, y postula "una cierta clase social, que resta determinar por las búsquedas sociológicas concretas" que experimentan, como el escritor, un "malestar afectivo" en la sociedad cosificada moderna (Goldmann, 1963: 182, 183). Ese malestar, se podría decir, se parece asombrosamente a la conciencia desventurada romántica ilustrada, entre otros, por el joven Lukács en La teoría de la novela.

\section{La modernidad y la novela en La teoría de la novela}

¿En qué consiste entonces el romanticismo de La teoría de la novela? Intentaremos demostrar que su estructura esencial se dispone alrededor de la siguiente proposición, eminentemente romántica (en su variante utópica): el mundo moderno burgués está radicalmente degradado en relación con las sociedades o las culturas que lo precedieron y el ser humano, que se mantiene sensible a los verdaderos valores encarnados en el pasado, no puede más que aspirar a una sociedad renovada en un futuro que restablecerá esos valores bajo una nueva forma.

En primer lugar, ¿cómo se define ese mundo moderno en el texto de Lukács? Goldmann destaca que este se refiere "apenas a las condiciones históricas" (Goldmann, 1962: 177); y es cierto que encontramos pocas caracterizaciones positivas de la época moderna, pero las que da son elocuentes. Hacia el final del libro, Lukács cita la frase de Fichte: "la época de la pecaminosidad consumada" (419), definiendo así a la modernidad como una caída en el mal en estado puro. Algunos pasajes indican su naturaleza global: "esencia puramente civilizatoria, ajena a la cultura, y en parte a su seca y estéril espiritualidad” (412), es la forma de sociedad que se encuentra en la Europa occidental (en contraposición a la Rusia que guarda algunos rasgos premodernos). Se caracteriza también por su "bajeza prosaica", y un pasaje especifica que se trata de la "sociedad burguesa actual".

Sin embargo, en La teoría de la novela la modernidad se define sobre todo negativamente, y en esto se revela la perspectiva romántica de su autor. Porque es la era de la ausencia, de la pérdida y de la nostalgia. Al no ser más que una "realidad inesencial y vacía”, eso que le falta, eso que se perdió para ella, es fundamental: la "totalidad" y la "comunidad". El mundo en donde el hombre moderno vive no es entonces "casa paterna, sino cárcel” (331) -formulación que recuerda al "estuche 
de acero" de Max Weber-. Sin comunidad y sin dioses, el hombre moderno está enteramente solo, preso de la nostalgia (expresada, entre otros, por los filósofos) y condenado a partir en la búsqueda de eso que, en el mundo moderno, no está más.

La novela pone en escena esa búsqueda, que tiene su origen en el carácter radicalmente inhóspito para el hombre del entorno moderno. A pesar de que en la mayoría de los casos Lukács utiliza el término romántico en relación con una sola de las variantes de la novela -el "romanticismo de la desilusión"- en un pasaje importante sugiere que ese origen de la novela lo identifica con el romanticismo en un sentido más amplio. Al señalar que el romanticismo alemán “ha puesto el concepto de novela, aun sin aclararlo siempre completamente, en íntima relación con el de lo romántico", asiente: "Y con mucha razón, pues la forma de la novela es, más que otra alguna, expresión del desamparo trascendental” (308). "El héroe de la novela, nace de aquella extrañeza respecto del mundo externo", insiste en otro pasaje (333).

La búsqueda que resulta de esto está fundada sobre "es abstracta la aspiración de los hombres a plenitud utópica, que no percibe como realidad verdadera, sino a sí misma y a su deseo" (337). Una búsqueda condenada al fracaso a causa de la decadencia radical del mundo moderno. El héroe que emprende la búsqueda es "demónico", es decir, deformado por la situación desesperada en la que se encuentra y si llega a veces a excesos terribles, se trata de que "crimen y locura son objetivación de la trascendental falta de patria” (328). El novelista es consciente del carácter ineludible del fracaso - del "paraíso eternamente perdido que se buscó y no se halló, y cuya búsqueda con resignado abandono ha redondeado el círculo de la forma" (352)-. De ahí, "la melancolía profunda de toda novela auténtica y grande" (352).

Lukács distingue tres grandes tipos de novela y cada uno expresa ese paradigma de manera diferente: "el idealismo abstracto", cuyo ejemplo más acabado es Don Quijote, el "romanticismo de la desilusión", ilustrado entre otros por La educación sentimental de Flaubert, y el Bildungsroman, con el ejemplo del Wilhelm Meister de Goethe. El último tipo es, contrariamente a los otros dos, el único que intenta una "síntesis" o "compromiso" entre las dos fuerzas totalmente opuestas en los otros tipos: el héroe y el mundo. No es seguro que Lukács lo vea como una falla en Goethe, pero al final del capítulo sobre el Wilhelm Meister insiste en que para ser válida la novela debe mostrar la realidad moderna tal como es, sin estetizarla: "no es posible elevar por la fuerza la realidad hasta ese nivel de sentido [...] y [...] no hay tampoco arte alguno de la configuración [...] como para superar ese abismo" (410).

\section{El paraíso perdido del pasado}

En oposición absoluta al "abismo" del presente -y el objeto de la nostalgia de aquellos que, viviendo en la modernidad, se mantienen al ritmo de los verdaderos valores humanos- se encuentran algunas grandes civilizaciones del 
pasado. La teoría de la novela comienza con una evocación de esas "civilizaciones cerradas”, y las primeras frases -ditirámbicas- marcan el tono:

\begin{abstract}
¡Felices los tiempos para los cuales el cielo estrellado es el único mapa de los caminos transitables y que hay que recorrer, y la luz de las estrellas única claridad de los caminos! Todo es para ellos nuevo y, sin embargo, familiar [...] El mundo es ancho $y$, sin embargo, como la casa propia, pues el fuego que arde en las almas es de la misma naturaleza que el de las estrellas (297).
\end{abstract}

En esas civilizaciones la alteridad del mundo, en relación con el ser humano que lo habita, está abolida. Este se siente en casa puesto que no hay diferencia de naturaleza entre su alma y el entorno de ese alma. Este entorno comprende, por lo demás, a la "naturaleza" extrahumana -el cielo estrellado-. En otro pasaje, Lukács habla de las dos "naturalezas" que se encuentran separadas en la modernidad: la "naturaleza" humana, constituida por el mundo de relaciones intrahumanas, y la que existe fuera de los seres humanos, esa naturaleza "salvaje”, frecuentemente buscada por los poetas románticos. Según Lukács, es solo en la modernidad, cuando el mundo de las relaciones humanas se corrompe, que una segunda naturaleza distinta -de las relaciones sociales- se encuentra escindida de la totalidad universal. En las civilizaciones "cerradas", esas dos naturalezas no hacen más que una y constituyen un verdadero "hogar" para el hombre.

El "cielo estrellado" sugiere también la presencia divina inmanente, que da un sentido último a la vida y muestra, de manera transparente, el camino a los hombres, revelándoles directamente cómo vivir. Eso que vuelve inútil a la filosofía: en esos tiempos no hay filósofos, o mejor dicho todos lo son, naturalmente. En cuanto a las relaciones de los hombres entre sí, forman parte de una comunidad unida, una "totalidad concreta, orgánica". Ese último adjetivo, bien entendido, se refiere a un concepto clave del romanticismo: la unicidad dinámica de los seres vivientes, en oposición al mecanismo y a la abstracción de las relaciones entre las cosas muertas y las entidades cuantitativas. En el seno de la comunidad orgánica, entonces, el hombre no está solo: "Sus relaciones con los demás y las formas que de ellas nacen son tan sustanciales como él mismo, y hasta más verazmente llenas de sustancia, porque son más generales [...] más cercanas a la patria prototípica y más emparentadas con ella: el amor, la familia, el Estado" (301).

La forma de la literatura épica que traduce ese universo del pasado es la epopeya. Ahora bien, de acuerdo con la naturaleza de ese entorno antiguo, el héroe de la epopeya no es un individuo aislado. El suyo "no es un destino personal, sino el de una comunidad" (333). Integralmente unido a una colectividad humana, y como representante de ella, el héroe está también íntimamente ligado al cosmos más amplio, impregnado de lo divino: en otra frase, tan lírica como la que abre La teoría de la novela, Lukács proclama que los protagonistas de la epopeya “discurren por sus caminos guiados por los dioses" (353). 
La plenitud perdida del pasado se manifiesta, de hecho, en dos épocas diferentes: la Grecia antigua y la Edad Media. La frase de Lukács que acabamos de citar toma como objeto específicamente a la primera, pero se aplicaría igualmente bien a la segunda, si reemplazamos “los dioses" por “Dios”. Al comienzo de La teoría de la novela, Lukács evoca la primera edad griega: "al misterio del helenismo, a su perfección, impensable desde nosotros, y a su insalvable extrañeza respecto de nosotros" (299). Sobre todo, es la época que ha producido a Homero, "cuyos poemas constituyen la única epopeya propiamente dicha [...] inigualable”, pero también la de los grandes trágicos. Las dos formas literarias, enraizadas en eso que Lukács -como muchos otros intelectuales modernos- concebía como la "juventud" desarrollada de la humanidad, encarnan una totalidad orgánica, cada una a su manera: en "la acción de la Ilíada, que no tiene ni comienzo ni final, un cosmos compacto florece a una vida que todo lo abarca" (322), y en la tragedia griega, donde "el coro y el corifeo han nacido del mismo fundamente esencial, se son homogéneos” (310).

La Edad Media constituye otro período privilegiado del pasado: “Así se hizo la Iglesia nueva polis [...] El mundo se vuelve a hacer redondo, dominable con la mirada, totalidad, con Giotto y Dante, Wolfram y Pisano, Tomás y Francisco" (305). A pesar de la tensión entre el mundo del pecado de aquí abajo y el reino de Dios, se creó un nuevo equilibrio no menos colorido y no menos acabado que el equilibrio griego. Dante, al final de ese período, representará, con la epopeya cristiana que es la Divina Comedia, su mayor expresión artística. Pero según Lukács se trata ya de una obra de transición hacia la modernidad: "Tiene aún la inmanente ausencia de distancias y la compacidad de la verdadera epopeya, pero sus figuras son ya individuos que se contraponen consciente y enérgicamente a un mundo que se cierra frente a ellos" (335).

Queda claro que la Grecia antigua y la Edad Media europea evocadas por Lukács están altamente idealizadas. Pero lo que importa, en lo que concierne a la visión romántica del mundo, no es el grado de realismo con el que los pasados mencionados son descriptos, sino más bien la cualidad de los valores humanos que simbolizan. Al identificar los valores de riqueza vital y de comunidad con esos momentos históricos, valores que ve como imposibles de realizar en la modernidad, Lukács da muestra de una sensibilidad profundamente romántica. Y es importante también notar, como lo reconoce el Lukács tardío del prólogo, que el autor de La teoría de la novela no es un romántico conservador o reaccionario sino, más bien, "utópico". Esto aparece claramente en un comentario hecho hacia el comienzo de la obra:

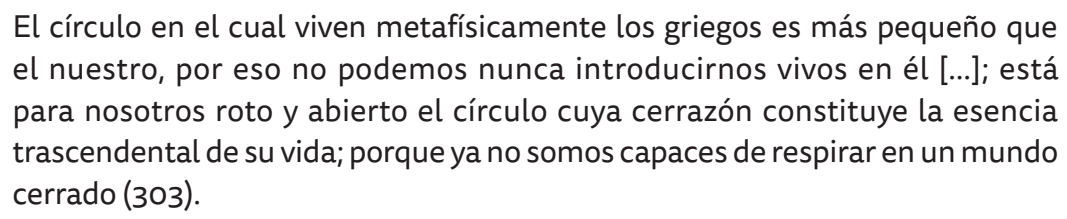

El círculo en el cual viven metafísicamente los griegos es más pequeño que el nuestro, por eso no podemos nunca introducirnos vivos en él [...]; está para nosotros roto y abierto el círculo cuya cerrazón constituye la esencia trascendental de su vida; porque ya no somos capaces de respirar en un mundo cerrado (303).

Ese comentario valdría, sin duda, igualmente para el mundo medieval, y significa que para el joven Lukács la trascendencia de la modernidad se inspiraría solamente en el pasado para crear un nuevo mundo. 


\section{La esperanza utópica: el último capítulo de La teoría de la novela}

En 1914-15 Lukács comienza a redactar las notas para un libro sobre Dostoievski. Ese proyecto se frustra y no llegará a concluir más que el primer capítulo, que es precisamente el texto que devino en La teoría de la novela. Lo que queda del proyecto inicial es un conjunto de notas dispersas, abandonadas en 1917 por Lukács en la célebre "valija de Heidelberg". Descubierto en 1973, ese material no será publicado hasta 1985, bajo el título de Anotaciones y bocetos sobre Dostoievski.

En ese manuscrito inconcluso y, a menudo, enigmático encontramos una especie de anarquismo romántico religioso, que se identifica con Sorel y Kierkegaard para denunciar al Estado, la Iglesia y toda forma de poder institucional. En esos fragmentos, Lukács se disocia del nacionalismo germánico, tan influyente entre sus contemporáneos: su expectativa romántica de "la luz que viene" (la aurora que surge) se vuelve sobre todo hacia Rusia. A sus ojos, el universo religioso del mundo ruso se opone al individualismo del mundo occidental (incluyendo Alemania): mientras que en Alemania el alma individual se vincula con Dios, en Rusia el alma de cada uno vive "en la comunidad, querida y creada por Dios, de las otras almas".

El esbozo contiene muchas referencias a Dostoievski sin constituir una visión de conjunto. Aparecen diferentes personajes de sus obras -Ivan Karamázov, el príncipe Myshkin, Raskólnikov- pero falta un argumento coherente sobre el escritor. Lukács piensa que Dostoievski no escribió novelas, y que su obra constituye una especie de "epopeya terrestre", comparable a la de Dante. Varios fragmentos comparan el pensamiento ruso en general, y el de Dostoievski en particular, con el pensamiento occidental. Asimismo, en un artículo sobre la cultura rusa publicado en 1916 en la revista de Max Weber, Lukács escribe: "los escritores de importancia histórico-mundial de Rusia quieren superar el individualismo 'europeo' (con la anarquía, la desesperación y la ausencia de Dios que acarrea), superarlo desde lo más profundo, y poner en el lugar conquistado a un hombre nuevo y, con él, un mundo nuevo" (Lukács, 1916-17: 978). Ese "mundo nuevo" será precisamente el horizonte utópico del último capítulo de La teoría de la novela.

La Stimmung, el estado intelectual, del joven Lukács al momento en que escribe La teoría de la novela asocia el rechazo categórico del presente con la conciencia aguda de la imposibilidad de un retorno al pasado. Proyectará, entonces, con la energía de la desesperanza, la nostalgia de la edad de oro perdida en una utopía del futuro. Es exactamente esa dialéctica utópica entre el pasado y el futuro, lo que define al romanticismo revolucionario del último capítulo del ensayo.

Su punto de partida es la insatisfacción con los límites de lo que él llama "visión romántica del mundo" -por ejemplo, Rousseau- cuya crítica de la cultura europea occidental queda a sus ojos como "puramente polémica, es decir, retórica". La superación de esa postura de simple rechazo no es posible en la Europa occidental. Esa disconformidad no deviene en creadora más que en la literatura rusa del siglo XIX, es decir, en Tolstoi y Dostoievski -los dos escritores favoritos del Círculo Max Weber de Heidelberg-. Estos autores, contrariamente a los de 
Occidente, están “más cerca de los estados orgánicos naturales antiguos" (organisch-naturhaften Urzustände) -una fórmula un poco enigmática que designa probablemente a las comunidades campesinas rusas (413)-.

La grandeza de Tolstoi radica en que pudo "captar los presentimientos de una apertura hacia una nueva época de la historia mundial”, aun "en el nivel del desacuerdo, de la nostalgia y de la abstracción”. Es solo en Dostoievski, "que no escribió novelas", que ese mundo nuevo "se encuentra por primera vez definido lejos de toda oposición contra lo que existe, como pura y simple visión de la realidad”. Así, Dostoievski es comparado por Lukács con los autores épicos del pasado, como una especie de bardo moderno: "Pertenece ya al mundo nuevo. Solo el análisis formal de sus obras permitirá saber si Dostoievski es ya el Homero o el Dante de ese nuevo mundo". La interpretación filosófico-histórica de su obra, y de sus continuaciones en el siglo XX, tendrá por tarea "resolver si estamos realmente a punto de abandonar el estadio de la pecaminosidad consumada 0 si son meras esperanzas las que anuncian la llegada de lo nuevo" (420).

Estas líneas, las últimas del libro, son bastante discutibles. Difícilmente se pueda negar que las obras de Dostoievski sean novelas, en las que "la oposición a eso que existe" ocupa un lugar esencial. Asimismo, la comparación con la Ilíada o la Divina Comedia aparece como demasiado artificial. Eso no impide que esta conclusión de La teoría de la novela sea un documento impresionante, por su "presentimiento de una apertura hacia una nueva época de la historia mundial" -la Revolución Rusa de octubre de 1917-.¿Cómo es que Lukács, a propósito de los escritores rusos Tolstoi y Dostoievski, en 1915-16, en plena “Unión Sagrada” de la guerra en todos los países europeos, cuando los revolucionarios más rigurosos no escapaban a la angustia cuando no a la desesperanza, ha podido formular no la intuición, sino el presentimiento de la revolución que se aproximaba y de su proyecto gigantesco de fundación de un "mundo nuevo"? Encontramos una intuición análoga, no menos sorprendente, en Lucien Goldmann, cuando descubre en 1966 (dos años antes del mayo del ‘68) en el teatro de Jean Genet "el síntoma de un giro histórico”, "la primera golondrina que anuncia la primavera" (Goldmann, 1966: 339).

Nostalgia de la edad de oro -ampliamente mítica- del pasado; rechazo ético del presente (burgués); aspiración a un "mundo nuevo": la estructura significativa de La teoría de la novela es justamente la de un romanticismo utópico, que renuncia a la ilusión de un retorno al paraíso perdido y coloca sus esperanzas sobre "la luz que viene". Sin duda, algunos de los desarrollos del libro que conciernen a la novela en general, la tipología de la forma novelística, o la trama de algunas novelas (por ejemplo, el Wilhelm Meister de Goethe), no tienen más que un vínculo indirecto con esa estructura. Desde nuestro punto de vista, la visión del mundo que se expresa en ese ensayo es la del romanticismo utópico. Ese utopismo -cuyo solo fundamento filosófico-histórico era la literatura rusa moderna, las obras de Tolstoi y Dostoievskia pesar de ser, como lo subraya con insistencia Lukács en 1962, "plenamente infundado" "abstracto" en su rechazo de la sociedad burguesa de la época, y sin ninguna mediación con la realidad objetiva, no deja de constituir una premonición sorprendente de los acontecimientos revolucionarios en Rusia dos años más tarde. 


\section{Q Bibliografía}

" Goldmann, L. (1963). Introduction aux premiers écrits de Georges Lukács. En La Théorie du roman. París: Gonthier.

" Goldmann, L. (1966). Le théâtre de Génet. Essai de lecture sociologique. En Structures mentales et création culturelle. París: Anthropos.

" Honigsheim, P. (1968). On Max Weber. Nueva York: Free Press.

"Löwy, M. y Sayre, R. (2008). Rebelión y melancolía: el romanticismo a contracorriente de la modernidad. Buenos Aires: Nueva Visión. Trad. de Graciela Montes.

"Löwy, M. (2010). Esprits de feu: figures du romantisme anti-capitaliste. París: Éditions du Sandre.

" Lukács, G. (1911). A Modern drama törtenéte. Budapest: Franklin. Vol. II.

" Lukács, G. (1916-1917). Solovieff. En Archiv für Sozialwissenchaft.

"Lukács, G. (1961). Zur Soziologie des modernen Dramas. En Schriften zur Literatursoziologie. Neuweid: Luchterhand.

"Lukács, G. (1985). El alma y las formas y Teoría de la novela. México DF: Grijalbo.

"Sayre, R. (2011). Romantisme et modernité: Parcours d'un concept et d'une collaboration. En Delacroix, V. y Dianteill, E. (eds.) Cartographie de l'utopie: l'œuvre indisciplinée de Michael Löwy. París: Éditions du Sandre. 